\title{
Impact of Snow and Ground Interference on Solar Photovoltaic Electric System Performance
}

\author{
N. Heidari, J. Gwamuri, T. Townsend, J.M. Pearce, Member, IEEE
}

\begin{abstract}
Assessing snow-related energy losses is necessary for accurate predictions of photovoltaic (PV) performance. A PV test platform with seven portrait-oriented modules placed at four tilt angles (0, 15, 30, and 45 degrees) was installed in Calumet, Michigan to measure the energy loss in this snowy climate. As a best-case snow-shedding configuration, three modules were elevated high enough to prevent surface interference. The opposite effect of maximum surface interference was introduced by mounting the other four modules at ground level. The platform was monitored for one year beginning in October 2013. The snowfall that winter was $5.3 \mathrm{~m}$ (209 inches). Snow-related annual energy losses ranged from $5 \%$ to $12 \%$ for the elevated, unobstructed modules, with the steepest tilt angle experiencing the least amount of energy loss. For the obstructed modules, there was proportionately less angular dependence on lost energy and annual energy losses ranged from $29 \%$ to $34 \%$. This relative $3-$ to 6-fold increase in lost energy when ground interference is present points out the importance of prompt snow clearing for portraitoriented PV. Depending on the breadth of an inverter's operating voltage limits, these results suggest that landscape-oriented array layouts and perhaps snow-clearing mechanisms may be advantageous in snowy climates.
\end{abstract}

Index Terms- Electricity; Energy loss; photoelectricity; photovoltaic cells; power systems; solar energy

\section{INTRODUCTION}

$\mathrm{S}_{\mathrm{o}}$ olar photovoltaic (PV) technology is a technically viable and environmentally beneficial solution to society's future electrical needs [1,2]. However, to optimize both the environmental [3-5] and economic [6-9] outcomes, including financing of PV systems, $[10,11]$ accurate prediction of system yields is critical and requires in-depth accounting of all loss mechanisms [12,13]. PV technology is increasingly being deployed in areas with low annual irradiation, like Northern Europe [3], and in regions that regularly experience snowfall, such as Germany, Japan, Canada, and the northern U.S. The accumulated snow on the modules affects the performance of the system and decreases the output power [14]. Previous studies indicate that annual snow losses for a low tilt angle system can easily reach or exceed $15 \%$. Even for an unobstructed, higher-slope (28 degree) roof mount system in

N. Heidari is in the Department of Electrical \& Computer Engineering, Michigan Technological University, MI (e-mail: heidari@mtu.edu)

J. Gwamuri is in the Department of Materials Science \& Engineering, Michigan Technological University, MI (e-mail: jgwamuri@mtu.edu )

T. Townsend is in the Renewables Advisory - Solar department, DNV GL, San Ramon, CA (e-mail: Tim.Townsend@dnvgl.com )
Germany, the losses, while smaller, could still range from 0.32.7\% [15-22]. As more of the better sites for PV are claimed (e.g., unobstructed rooftops and high-rack ground mounts), lesser-grade sites such as those subject to frequent snows will become more popular. To quantify the snow loss effect, a test site has been designed and deployed in a heavy snow location to investigate PV electricity generation losses as a function of tilt angle and snow sliding obstruction geometry.

\section{Methodology}

A system has been developed to investigate the effects of snow on the performance of photovoltaic modules as a function of tilt angle and degree of ground interference. The system was deployed at the Keweenaw Research Center (KRC) located in Calumet, MI USA, and webcam archived images are freely available to the public [23]. The study has been conducted on seven $140 \mathrm{~W}$ Kyocera (KD140) poly-Si modules. Four modules are mounted at ground level at angles of $0,15,30$, and 45 degrees, with no ground clearance. Three other modules are on a raised rack with a ground clearance of $1.5 \mathrm{~m}$, at angles of 15 , 30 , and 45 degrees. To simulate the effect of the modules being in a large array, a $30 \mathrm{~cm}$ border of blue metal shielding was applied around each module. The layout of the test site is shown in Fig 1. It should be pointed out that only one module at zero degree tilt angle is needed, as the same snow losses are expected for a well-bordered horizontal module that is either elevated or mounted close to the ground.

Each PV module was monitored for temperature ( $\mathrm{T}$ ) with an accuracy of $+/-0.9^{\circ} \mathrm{C}$ and for short-circuit current $\left(\mathrm{I}_{\exp }(\mathrm{T})\right)$ with an accuracy of $+/-1 \%$. All measurements were carried out at $15-$ minute intervals. Solar irradiance $\left(\mathrm{P}_{\text {sun }}\right)$ was measured using four LI-COR Li-200SA pyranometers mounted on individual panels for each angle. The pyranometer uncertainty is $\pm 5 \%$ [24,25]. The parameters $P_{25} \mathrm{C}, I_{\text {exp25' } \mathrm{C}}, T_{25^{\prime} \mathrm{C}}$, and $\mathrm{T}_{\mathrm{C}}$ are obtained from the module manufacturer's data sheet [26]. The short-circuit current data for the seven PV modules was recorded for the year starting in October 2013 and analyzed for the entire year and also over a subset of it encompassing just the Fall 2013 and Spring 2014 snow season (November 2013 May 2014). The total snowfall recorded for this period was 209 inches [27]. The 2013-14 snowfall of 209 inches was $15 \%$ above the past 5 -year average, but $4 \%$ below the 40 -year

J.M. Pearce is in both the Department of Electrical \& Computer Engineering and Department of Materials Science \& Engineering, Michigan Technological University, MI Corresponding author: 601 M\&M Building, 1400 Townsend Drive, Houghton, MI 49931-1295 (e-mail: pearce@mtu.edu). 
average. The recorded amount can be viewed as typical, since it fit well within the long-term standard deviation of $\pm 25 \%$ for annual snowfall at this location as seen in Table I.

TABLE I

HISTORIC SNOWFALL RECORD FOR KEWEENAW RESEARCH CENTER

\begin{tabular}{|c|c|c|}
\hline Year & $\begin{array}{c}\text { Annual snowfall } \\
\text { (inches) }\end{array}$ & Comment \\
\hline $2013-14$ & 209 & $\begin{array}{c}15 \%>5 \text {-yr avg. } \\
4 \%<40 \text {-yr avg. }\end{array}$ \\
\hline 5-year avg & $181 \pm 34$ & $\begin{array}{c} \pm 19 \% \text { variation } \\
@ 1 \sigma\end{array}$ \\
\hline 40 -year avg & $218 \pm 54$ & $\begin{array}{c} \pm 25 \% \text { variation } \\
@ 1 \sigma\end{array}$ \\
\hline $\begin{array}{c}40 \text {-year low: } \\
\text { 2011-12 }\end{array}$ & 132 & $39 \%<40$-yr avg. \\
\hline $\begin{array}{c}40 \text {-year high: } \\
\text { 1978-79 }\end{array}$ & 356 & $63 \%>40$-yr avg. \\
\hline
\end{tabular}

Townsend and Powers developed equations to calculate monthly energy loss as a function of climate and array geometry [15]. Others, including the authors above, have attempted to correlate snow-related energy loss on shorter hourly or daily time scales, with significant limitations. The focus of this study is on monthly results, though individual measurements are recorded on 15-minute intervals. Here power is not directly measured, but is estimated. This is done by relying on pyranometer and temperature data in the first case, and in the other case, by relying on short-circuit current and temperature data. In both cases, the field measurements must be supplemented with manufacturer's specifications for the module and the pyranometers (in this case, Kyocera $140 \mathrm{~W}$ poly-Si type modules, with 36 cells in series, and LI-COR Li200SA pyranometers).

The power from each snow-exposed module at each 15-minute interval was calculated as:

$P_{m}=\frac{I_{\exp }(T)\left(P_{25^{\circ} \mathrm{C}}\left(1+C\left(T-T_{25^{\circ} \mathrm{C}}\right)\right)\right)}{I_{\exp 25^{\circ} \mathrm{C}}\left(1+\alpha\left(T-T_{25^{\circ} \mathrm{C}}\right)\right)}$

By considering the flash-tested power rating of the modules and the irradiance obtained from the pyranometers at each angle, the potential clean-module power that can be extracted at each tilt angle is then determined using equation (2) below:

$P_{c}=\left(P_{\text {sun }}\left(1+\beta\left(T_{25^{\circ} \mathrm{C}}-T\right)\right)\right) \times \frac{P_{25^{\circ} \mathrm{C}\left(1+C\left(T-T_{25^{\circ} \mathrm{C}}\right)\right)}}{1000}$

In the equation above, either the reference irradiance of 1,000 $\mathrm{W} / \mathrm{m}^{2}$ or the measured irradiance should be corrected for temperature. As the reference irradiance is normally viewed as a constant, here the measured irradiance is adjusted to see what it would have been under the same conditions that the reference irradiance was measured at, $25^{\circ} \mathrm{C}$. The module power, however, is sought for the field temperature, not the reference temperature, so that temperature adjustment is the same as the one done for the snowy module. The energy loss due to snow is calculated as the difference in energy without snow, $\mathrm{P}_{c}$, versus the energy obtained from snow covered modules, $\mathrm{P}_{m}$ :

$E_{\text {loss }}(t)=\left(P_{c} \times t\right)-\left(P_{m} \times t\right)$

\section{A. Abbreviations and Acronyms}

$\alpha$ : Temperature Coefficient of Current, module [1/C]

$\beta$ : Temperature Coefficient, pyranometer $[1 / \mathrm{C}]$

C: Temperature Coefficient of power, module [1/C]

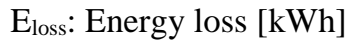

$\mathrm{I}_{\text {exp }}(\mathrm{T})$ : Short-circuit current measured at experimental temperature [Amps]

$I_{\exp 25^{\prime} \mathrm{C}}$ : Short-circuit current at Standard Test Condition [Amps]

$\mathrm{P}_{\mathrm{c}}$ : Power that can be extracted from each (hypothetical) clean module (without snow) [Watts]

$\mathrm{P}_{\mathrm{m}}$ : Calculated output power of snow-exposed module (at various angles and heights) [Watts]

$\mathrm{P}_{\text {sun: }}$ Irradiance obtained by pyranometer (at various angles) [Watt $\left./ \mathrm{m}^{2}\right]$

$P_{25}{ }^{\circ}$ : Maximum power of flash-tested modules at STC, nominally $140 \mathrm{~W}$ [Watts]

$\mathrm{T}$ : Experimental Temperature [Celsius]

$T_{25^{\prime} \mathrm{C}}$ : Temperature at Standard Test Conditions (STC) $25^{\circ} \mathrm{C}$ [Celsius]

$\mathrm{t}$ : Time Stamp, (15 minutes was used for this test) [Hours]

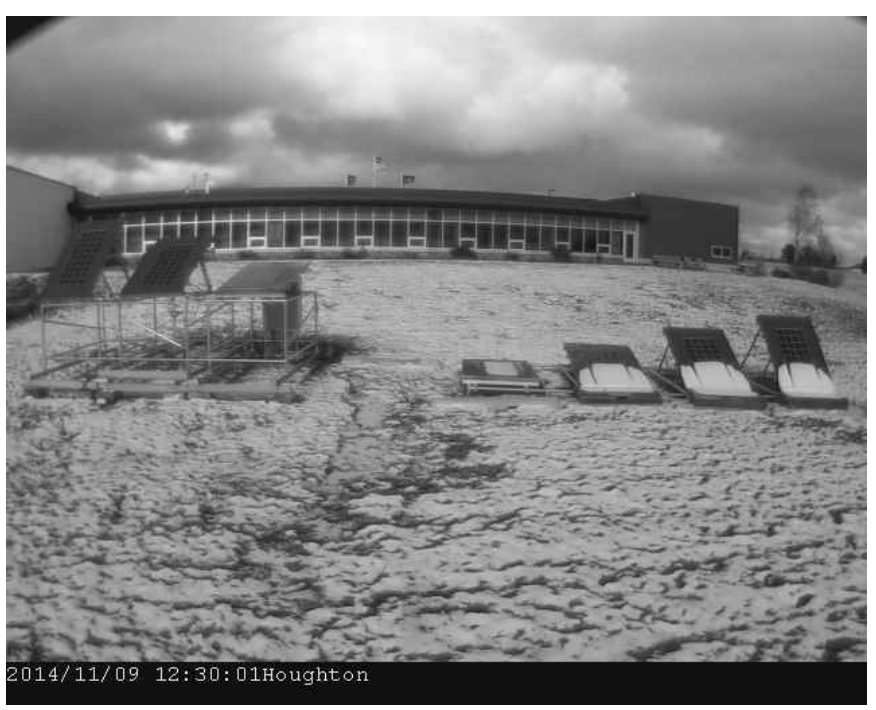

Fig. 1. 7-module snow test platform at the Keweenaw Research Center

\section{RESULTS AND DISCUSSION}

Fig. 2 below shows the yearly energy loss for the seven module positions, while Fig. 3 presents the same results, but limited to the snow season months of November-May. Fig. 2 shows that as the tilt angle increased from zero to 45 degrees in the unobstructed cases, the yearly energy loss decreased from $34 \%$ to just $5 \%$. However, in the case of obstructed modules, that trend is not apparent, as the losses appear to be similarly clustered in the $29-34 \%$ range. At low angles, the obstructed case results are similar to the unobstructed case, and at zero tilt, are deemed to be identical. Measurement error obscures some of the true trend, but even at 45 degrees, the loss percentage remains very high. Even though snow readily slides off the 
steeply tilted module, if it remains piled up at the base it will still cause a near- $100 \%$ loss of power as long as even one cell in the 36-cell string is shaded.

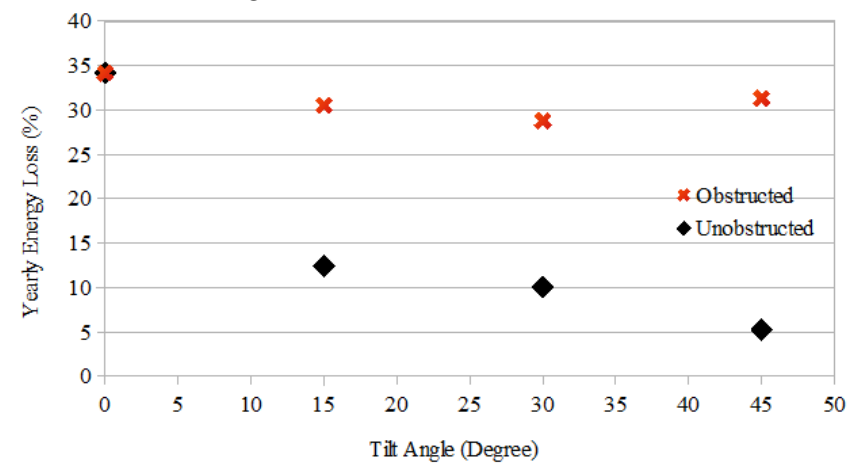

Fig. 2. Yearly energy losses due to snow for obstructed and unobstructed photovoltaic modules located in Calumet, MI.

Energy loss for the 45 degree unobstructed module was $5.2 \%$, while the loss for the obstructed module with the same tilt angle was $31.3 \%$. This represents a six-fold worsening of lost energy (a 26.1\% absolute annual loss) for this extreme obstruction geometry. At the 30-degree tilt, the loss magnification is less severe, just a three-fold difference, but still represents an additional absolute annual loss of $18.8 \%$ (10\% and $28.8 \%$ for the unobstructed and obstructed cases, respectively). Results for the 15-degree tilt were about the same as for the 30-degree situation, and the worst-case loss of $34 \%$ occurred for the zero-tilt case, as expected.

Fig. 3 shows that energy losses during the snow season follow the same relative trend as for the yearly energy losses depicted in Fig. 2. However, on a fractional basis, the energy losses in the snow season (November - May in the Upper Peninsula of Michigan) are higher due to the reduced winter solar resource. The error for the measurements was small and can be attributed to dust or snow accumulation on the pyranometer. This error would bias the reported energy losses to be slightly lower than they actually were. Finally, daily energy losses in $\mathrm{kWh}$ from mid-October 2013 to mid-October 2014 for each module have been plotted, and the results for the worst case (obstructed with the tilt angle of 45), and the best case (unobstructed with the tilt angle of 45 ) are presented in Figs. 4 and 5, respectively.

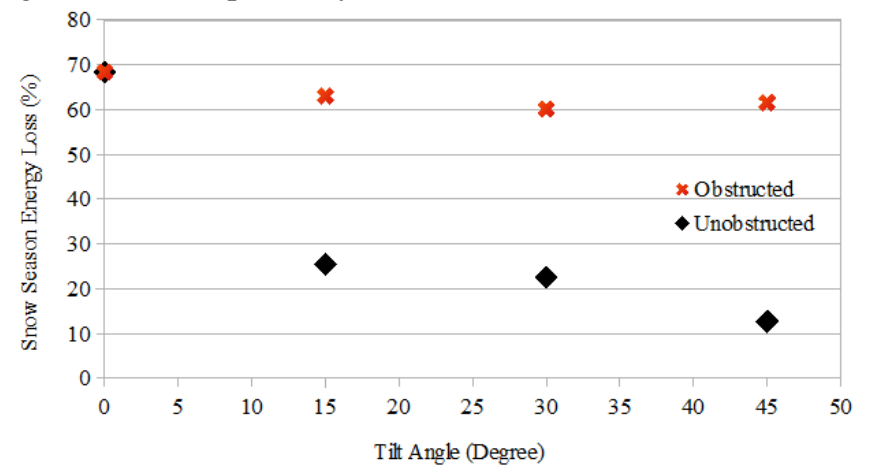

Fig. 3. Snow season (November to May in the Upper Peninsula of Michigan) energy losses for obstructed and unobstructed solar photovoltaic modules in Calumet, MI.

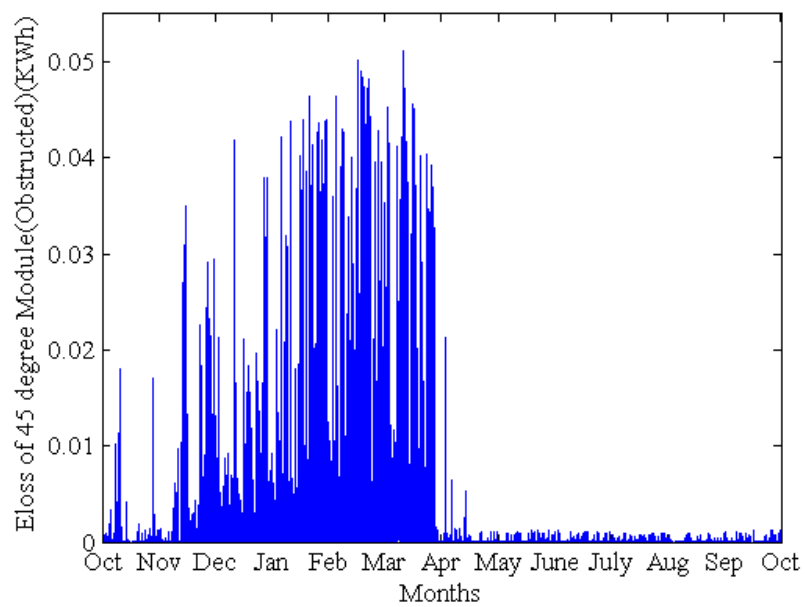

Fig 4. Daily energy loss, in kWh, for the obstructed module with the tilt angle of 45 degree throughout the year in Calumet, MI.

Figures 4 and 5 show the daily effect of module snow cover on PV system electricity generation capacity. It can be observed by comparing the obstructed and unobstructed modules of the same angle that the power for the unobstructed module (Fig. 5) rapidly returns to full power after each snowfall event. Fig. 4, on the other hand, shows significant and persistent losses through the entire snowy season, especially in February and March, as the module rarely became clear enough to deliver full power.

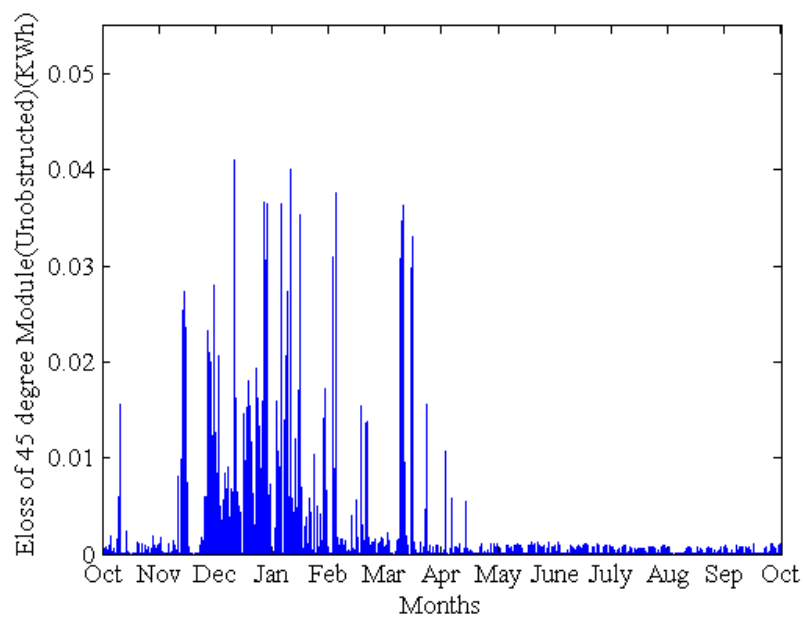

Fig 5. Daily energy loss, in kWh, for the unobstructed module with the angle of 45 degree

Since the accumulation of snow on the modules has such a strong effect on the performance of the modules [14], the proper assessment of energy losses have become important for improving the electrical performance of the system and understanding its economic performance [21]. Many of the studies that have investigated snowfall have been in less snowy areas or have been conducted during low-snow periods. For example, in [21], 70 modules with different technologies oriented at different angles were monitored for two winters near Toronto, Ontario, Canada to obtain energy losses. Yearly losses ranged from $1-3.5 \%$, which is small in comparison to the present study, which finds yearly losses ranged from 5-34\%, 
indicating that energy losses in the Michigan UP region are significantly higher than other regions with typically half of the normal snowfall, like Toronto. It should be noted the years for the Ontario study were abnormally warm and had little snow.

Townsend and Powers conducted a study in Truckee, California, which receives about 200 inches of snow annually. Data were obtained at three tilt angles for pairs of modules, one of which was kept clean and one which was allowed to gather and shed snow as prevailing weather conditions dictated. The snow-exposed modules were mounted about $0.5 \mathrm{~m}$ above grade, so pile-up interference happened often, but not always [15]. Data were also available for a similarly oriented system located just $3 \mathrm{~km}$ away, but which had no ground interference. The annual losses were found to be $6 \%$ for the no-interference, 35degree tilt system. These losses increased to $13 \%, 17 \%$, and $26 \%$ for the test station's angles of 39, 24, and 0 degrees, respectively. These values are in agreement with the results from the current study. Other studies found that annual snow losses for a low profile system can easily reach or exceed $15 \%$. Even for an unobstructed, higher slope (28 degree) roof mount system, the losses, while smaller, could still range from 0.32.7\% [15-22].

In order to improve performance of the PV systems in snowy climates like this region, obstructed PV systems should not be used, unless heavy snow-related losses are viewed beforehand as acceptable or a method of clearing them is deployed. This will, for example, limit some rooftop applications, as in this area they can result in a yearly energy loss of $30 \%$ even for high tilt angles. The results of this study also indicate that the physical orientation and electrical stringing of the modules is important. For example, when the modules are partially covered with snow (as the obstructed modules are on the right of Fig. 1), the current was decreased by a much larger percentage than the percent of module area that the snow covered. In this study, the modules were all oriented in portrait layout, resulting in the bypass diodes becoming ineffective during periods of partial shading. This affected the output power of modules giving the worst case scenario of power loss of up to $92 \%$ (or more, depending on the thickness of snow cover) [28]. This problem could be partly alleviated by orienting the modules in landscape format. Landscape format enables bypass diodes to nominally skip one-third of the obstructed cells at a time, and if the microinverter or string inverter can operate at a reduced dc input voltage, the system can operate. However, this study was not constructed to quantify this more shade-tolerant geometry and future work is needed to quantify this loss. [29].

At the KRC site, the pyranometers were heated to help melt off the snow, and technicians were available to clean the pyranometers after a snow event. The data were screened to see if there were occasions when the pyranometers were covered with snow. This was done by comparing readings of sun-facing pyranometers (located at 0,15 , and 30 , and 45 degree modules) with the readings of a downward-facing pyranometer (from the back of the elevated 45 degree module). The main purpose for this pyranometer is to serve as a quality check against irradiance measurements made on the sun-facing front sides of the frames. The rear-facing module is shielded from snow and during daylight hours should always read a small positive number. If the down-facing pyranometer had a higher value than the readings of a sun-facing pyranometer, it was likely because the sun-facing pyranometer was being affected by snow. In order to compare the readings, whenever the reading of the sun-facing pyranometer was less than $90 \%$ of the reading of the downward-facing pyranometer, then the sun-facing pyranometer was assumed to be covered with snow. The hours that pyranometers were covered with snow in the winter were found to be $2,13.5,12$, and 1.5 hours for pyranometers located at the $45,30,15$, and 0 degree modules respectively. There were also times that pyranometers were covered with snow for 15 minutes or half an hour during snow fall events and were then either cleaned or self-cleaned by wind, but these brief, low-tozero irradiance periods were of trivial numerical impact on the analysis and were not considered among the total hours that the pyranometers were deemed to be covered with snow.

Future work is also necessary for investigating how snow affects low-concentration systems, which have been proposed [30]. In these setups, a reflector is attached from the back top of one row of modules to the front bottom of the next. Normally all reflectors are flush. If the reflectors are utilized at the back of the modules to enhance system electrical generation [31,32], they will need to be spaced out far enough from the modules to allow for snow to slide off.

Finally, all systems could benefit from an active method to clear snow. Thus future work is needed to quantify the effectiveness of different forms of cleanings such as melting off the snow [33,34], chemical coatings [35], using squeegees [36], and tennis balls divots to catalyze clearing [37] to reduce the snow-related energy losses. This work involves experimental and economic analysis of these snow removal techniques.

\section{CONCLUSIONS}

In this paper, energy losses of PV systems with different architectures and tilt angles were quantified for a test site located in Calumet, Michigan. It was seen that energy losses due to snowfall are significantly dependent on the tilt angle and the degree of ground interference. The study indicated that annual energy losses decreased dramatically, from 34\% to 5\%, as tilt angle increased from zero to 45 degrees for unobstructed systems. For obstructed systems, annual energy loss hovered in the $30-34 \%$ loss range, regardless of tilt angle. This suggests the role of ground interference varies from no impact on flat-tilt systems to a six-fold worsening for 45-degree tilt systems. This one-year study (2013-14) showed that snow-related energy losses ranged from $5 \%$ to $12 \%$ for three elevated modules and from $29 \%$ to $34 \%$ for comparably tilted modules mounted next to the ground. The 2013-14 snow season was slightly higher than the 5-year average preceding it but slightly lower than the 40-year average, so future losses for this location should be roughly comparable to this study's findings. Current results serve to inform PV system design and optimizations in this and other locations with similar weather patterns. The study is still ongoing to better home in on long-term expected performance. It was found that proper assessment of energy losses due to snowfall can significantly improve understanding of system economics and also highlight possible ways to improve performance by actively cleaning the modules. It can be surmised that in this region, higher tilt angles of around 45 degrees and unobstructed snow shedding geometries are 
Preprint: Heidari, N., Gwamuri, J., Townsend, T.,Pearce, J.M. (2015). Impact of Snow and Ground Interference on Photovoltaic Electric System Performance. IEEE Journal of Photovoltaics 5(6),1680-1685, (2015). doi:10.1109/JPHOTOV.2015.2466448

recommended in order to keep annual energy loss to an acceptable level.

\section{ACKNOWLEDGMENTS}

The authors would like to thank the generous support of the Keweenaw Research Center and DNV GL for materials and labor to perform this work.

\section{REFERENCES}

[1]. J. M. Pearce, "Photovoltaics—a path to sustainable futures," Futures, 34(7), 663-674, 2002.

[2]. V. Fthenakis, J. E. Mason, and K. Zweibel, “The technical, geographical, and economic feasibility for solar energy to supply the energy needs of the US,” Energy Policy, vol. 37, no. 2, pp. 387-399, Feb. 2009.

[3]. R. Laleman, J. Albrecht, and J. Dewulf, "Life Cycle Analysis to estimate the environmental impact of residential photovoltaic systems in regions with a low solar irradiation," Renewable and Sustainable Energy Reviews, vol. 15, no. 1, pp. 267-281, Jan. 2011.

[4]. R. Kenny, C. Law, and J. M. Pearce, "Towards real energy economics: Energy policy driven by life-cycle carbon emission,” Energy Policy, vol. 38, no. 4, pp. 1969-1978, Apr. 2010.

[5]. E. Nieuwlaar, and E. Alsema, "International Energy Agency, and Photovoltaic Power Systems", Environmental aspects of $P V$ power systems: report on the IEA PVPS Task 1 Workshop, 25-27 June 1997, Utrecht, the Netherlands. Utrecht, the Netherlands: Utrecht University, 1997.

[6]. K. Branker, M. J. M. Pathak, and J. M. Pearce, "A review of solar photovoltaic levelized cost of electricity," Renewable and Sustainable Energy Reviews, vol. 15, no. 9, pp. 4470-4482, Dec. 2011.

[7]. K. Branker, E. Shackles, and J. M. Pearce, "Peer-to-peer financing mechanisms to accelerate renewable energy deployment" Journal of Sustainable Finance \& Investment. vol. 1, no. 2, pp. 138-155, 2011.

[8]. J. D. Mondol, Y. G. Yohanis, and B. Norton, "Optimising the economic viability of grid-connected photovoltaic systems," Applied Energy, vol. 86, no. 7-8, pp. 985-999, Jul. 2009.

[9]. J. D. Mondol, and S. K. Hillenbrand, "Grid parity analysis of solar photovoltaic systems in Europe," International Journal of Ambient Energy, 35(4), 200-210, 2014.

[10]. N. Ameli, and D. M. Kammen, "Innovations in financing that drive cost parity for long-term electricity sustainability: An assessment of Italy, Europe's fastest growing solar photovoltaic market” Energy for Sustainable Development, 19, 130-137, 2014.

[11]. T. Alafita, and J. M. Pearce, "Securitization of residential solar photovoltaic assets: Costs, risks and uncertainty,” Energy Policy, 67, 488-498, 2014.

[12]. M. Mani and R. Pillai, "Impact of dust on solar photovoltaic (PV) performance: Research status, challenges and recommendations," Renewable and Sustainable Energy Reviews, vol. 14, no. 9, pp. 31243131, Dec. 2010.

[13]. D. Thevenard, A. Driesse, D. Turcotte, and Y. Poissant, " Uncertainty in Long-Term Photovoltaic Yield Predictions” Technical Report 2010- 122 (RP-TEC) 411-IEARES. CanmetENERGY, Natural Resources Canada, Mar, 2010.

[14]. S. Meghdadi and T. Iqbal, "A Low Cost Method of Snow Detection on Solar Panels and Sending Alerts," Journal of Clean Energy Technologies, vol. 3, no. 5, pp. 393-397, 2015.

[15]. T. Townsend and L. Powers, "Photovoltaics and snow: An update from two winters of measurements in the sierra," in Photovoltaic Specialists Conference (PVSC), 2011 37th IEEE, 2011, pp. 003231-003236.

[16]. G. Becker, B. Schiebelserger, W. Weber, J. Schumacher, M. Zehner, G. Wortuba, and C. Vodermayer, "Energy yields of PV systems-comparison of simulation and reality," 23rd European Photovoltaic Solar Energy Conference and Exhibition, 1-5 September 2008, Valencia, Spain.

[17]. B. Marion, J. Adelstein, K. Boyle, H. Hayden, B. Hammond, T. Fletcher, B. Canada, D. Narang, A. Kimber, L. Mitchell, G. Rich, and T. Townsend, "Performance parameters for Grid-Connected PV systems" In: 31st IEEE Photovoltaics Specialists Conference and Exhibition, pp. 1-5, Feb 2005.

[18]. M. M. D. Ross, "Snow and ice accumulation on photovoltaic arrays: An assessment of the TN conseil passive melting technology, report\# EDRL
95-68 (TR), energy diversification research laboratory, CANMET," Natural Resources Canada, Varennes, 1995.

[19]. B. L. Brench, "Snow-Covering Effects on the Power Output of Solar Photovoltaic Arrays” DOE DE-AC02-76ET20279, 1979.

[20]. R. W. Andrews, and J. M. Pearce, "Prediction of energy effects on photovoltaic systems due to snowfall events," In Photovoltaic Specialists Conference (PVSC), 2012 38th IEEE. pp. 003386-003391. June. 2012.

[21]. R. W. Andrews, A. Pollard, and J. M. Pearce, "The effects of snowfall on solar photovoltaic performance," Solar Energy, 92, 84-97, 2013.

[22]. L. Powers, J. Newmiller, and T. Townsend, "Measuring and modeling the effect of snow on photovoltaic system performance," In Photovoltaic Specialists Conference (PVSC), 2010 35th IEEE. pp. 000973-000978. June. 2010.

[23]. Webcam Images, Index of /webcam2. [Online]. Available: http://mtukrc.org/webcam2/. Accessed on: Mar. 26, 2015.

[24]. LI-COR, "Pyranometer Light Sensors," 2015. [Online]. Available: http://www.licor.com/env/products/light/pyranometers/. Accessed on: Mar. 27, 2015.

[25]. Pyranometer Specsheet, LI-200SA Pyranometer Sensor. [Online]. Available: http://www.licor.com/env/pdf/light/RMB.pdf

[26]. Module Spec sheet, High Efficiency Multicrystal Photovoltaic Module. [Online]. Available: http://www.kyocerasolar.com/assets/001/5340.pdf

[27]. Michigan Tech Alumni Association,"Snowfall Records,"2015. [Online]. Available: http://www.mtu.edu/alumni/favorites/snowfall/. Accessed on: Mar. 26, 2015.

[28]. C. Barreiro, P. M. Jansson, A. Thompson, and J. L. Schmalzel, "PV bypass diode performance in landscape and portrait modalities," in Photovoltaic Specialists Conference (PVSC), 2011 37th IEEE, 2011, pp. 003097-003102.

[29]. P. Bulanyi, R. Zhang, "Shading Analysis \& Improvement for Distributed Residential Grid-Connected Photovoltaic Systems". Presented at Solar2014: The 52nd

Annual Conference of the Australian Solar Council. [Online]. Available: https://www.sicleanenergy.com.au/wp-content/uploads/2014/05/ShadeEffect-Paper_Final-1.pdf

[30]. R. W. Andrews, N. Alazzam, and J. M. Pearce, "Model of Loss Mechanisms for Low Optical Concentratioon on Solar Photovoltaic Arrays with Planar Reflectors," in 40th American Solar Energy Society National Solar Conference Proceedings, pp. 446-453, 2011.

[31]. A. B. Ajayi, O. A. Majekodunmi, A. S. Shittu, "Comparison of Power Output from Solar PV Panels with Reflectors and Solar Tracker," in Journal of Energy Technologies and Policy. Vol. 3, No. 7, pp. 70-77, 2013.

[32]. T. Blakeslee, "Reflectors Significantly Raise the Efficiency of Flat Rooftop Solar," Sept. 23, 2013. [Online]. Available: http://www.renewableenergyworld.com/rea/blog/post/2013/09/reflectors -significantly-raise-the-efficiency-of-rooftop-solar

[33]. Intelligent \& self-cleaning solar panels, by G. Mckarris. (2012. Nov 15). Patent US20120285516 A1 [Online]. Available: http://www.google.com/patents/US20120285516

[34]. Heated Solar Panel System and Method, by G. A. Van Straten. (2015. Jan 22). Patent US20150021310A1 [Online]. Available: http://www.freepatentsonline.com/y2015/0021310.html

[35]. R. W. Andrews, A. Pollard, J. M. Pearce, "A new method to determine the effects of hydrodynamic surface coatings on the snow shedding effectiveness of solar photovoltaic modules". in Solar Energy Materials and Solar Cells, Vol. 113, pp. 71-78, 2013.

[36] The Solar Company, "5 Methods to Remove Snow Off Solar Panels," June. 8, 2012. [Online]. Available: http://www.thesolarco.com/5methods-to-remove-snow-off-solar-panels/. Accessed on:Mar. 27, 2015.

[37]. United States Weather, "Are Solar Panels Usable in Snowy Climates?," Jan 2, 2015. [Online]. Available:

http://www.accuweather.com/en/weather-news/are-solar-panels-usablein-sno/21894748, Accessed on: Mar. 26, 2015. 


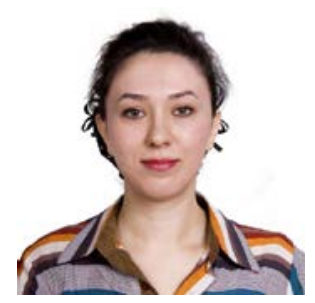

Negin Heidari received her bachelor's degree in Electrical Engineering from Azad University of Kerman.

She is currently a Master student at Michigan Technological University. Her research activities include the investigation of impact of snow and ground interference on the performance of PV systems, liability of greenhouse gas emissions, energy production calculation for large scale PV systems, modeling and simulation of microgrids, wind turbines, and batteries.

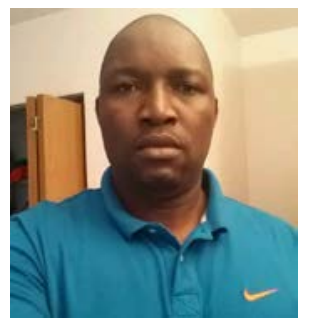

Jephias Gwamuri was born in Lupane, Zimbabwe, in 1970. He received his B.S. degree in Physics and Electronics from ISP "Enrique Jose Varona”, Cuba, and his M.Sc in Lasers and Applied Optics from NUST, Bulawayo in Zimbabwe in 2004. He is currently pursuing his Ph.D. degree in material science and engineering at Michigan Tech, Houghton, MI.

From 2006 to 2012, he was a lecture at the National University of Science and Technology, Bulawayo, Zimbabwe. Since 2012, he has been a PhD research fellow with the Material Science and Engineering Department, Michigan Technological University, Houghton. His research interests include novel thin film PV devices, renewable energy technologies, energy efficiency and sustainability.

Mr. Gwamurir was a recipient of the SPIE best student poster presentation and OSA student award. He also received the Fulbright Science and Technology award - PhD fellowship in 2012.

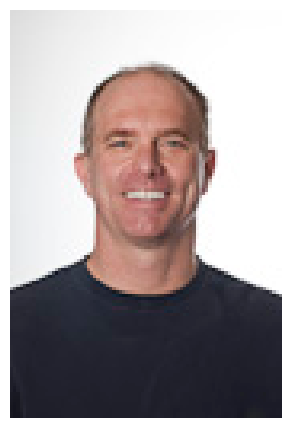

Tim Townsend received his B.S. in thermal \& environmental engineering from Southern Illinois Univ.-Carbondale and his M.S. in mechanical engineering from the Univ. of Wisconsin-Madison.

He performed O\&M and monitoring for over a decade at the landmark PVUSA utility-scale PV demonstration project in Davis, CA, authoring several conference papers stemming from that project. He has provided PV training for over 2,000 journeyman electricians, and contributed (as principal author) the "PV Systems" chapter of the Handbook of PV Science and Engineering ( ${ }^{\text {nd }}$ ed., Wiley \& Sons, 2011). In 2005, he established today's common style for PV Independent Engineering (IE) analysis and reporting, including applying PVsyst as the preferred modeling platform for aiding investor decision-making. Part of his recent and ongoing IE work has included designing a PV snow loss experiment at Truckee, CA; this resulted in the first and still sole model for predicting monthly PV snow loss [15] and was the impetus for this paper with MI Tech.

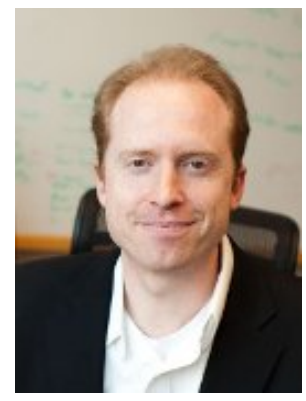

Joshua M. Pearce received his Ph.D. in materials engineering from the Pennsylvania State University.

He then developed the first Sustainability program in the Pennsylvania State System of Higher Education as an assistant professor of Physics at Clarion University of Pennsylvania and helped develop the Applied Sustainability graduate engineering program while at Queen's University, Canada. He currently is an Associate Professor cross-appointed in the Department of Materials Science \& Engineering and in the Department of Electrical \& Computer Engineering at the Michigan Technological University where he runs the Open Sustainability Technology Research Group. His research concentrates on the use of open source appropriate technology to find collaborative solutions to problems in sustainability and poverty reduction. His research spans areas of electronic device physics and materials engineering of solar photovoltaic cells and systems, and 3-D printing, but also includes applied sustainability and energy policy. Dr. Pearce is the author of the Open-Source Lab: How to Build Your Own Hardware and Reduce Research Costs (Elsevier, 2013). 